\title{
Optimization of dimethyl ether production process synthesis using superstructure analysis
}

\author{
Teerapat Laiwatthanaphaisarn and Amata Anantpinijwatna* \\ Department of Chemical Engineering, Faculty of Engineering, King Mongkut's Institute of Technology Ladkrabang, \\ Bangkok, Thailand
}

\begin{abstract}
Current world energy consumption is likely to increase over time. This is due to the growth of industry and transportation. The most important and most used energy sources are crude oil and natural gas. The consumption of energy is increasing continuously due to the economic expansion of the world fleet. At present, prices of primary energy sources such as oil and natural gas tend to increase. In addition, oil and gas are limited and likely to run out in the future. Currently, research and research on alternative energy is ongoing. To find the best alternative energy to replace in the future. Dimethyl ether is a substance that can be used as a substitute for liquefied petroleum gas (LPG) because of its similar physical properties. Most of them are used as fuel in vehicles. In addition, dimethyl ether is easier to liquefy than liquefied petroleum gas, giving advantages in terms of storage and transport, and a higher cetane value that can be used in the vehicle. Dimethyl ether is a substance that will burn completely. Dimethyl ether production has a wide variety of options. If the best option is difficult to analyse because of the complexity of the solution. Superstructure analysis will help to find alternatives for the production of dimethyl ether. Superstructure will identify the most economical alternative. The mathematical model is applied to the existing production process and new alternatives. In this work, the alternatives to produce dimethyl ether are displayed and the optimum alternative are chosen.
\end{abstract}

\section{Introduction}

Current world energy consumption is likely to increase over time due to the growth of industry and transportation. The most important energy sources are crude oil and natural gas which are globally consumed at approximately 5,700 million tons equivalent of crude oil per year [1]. At present, prices of primary energy sources such as oil and gas are in an increasing trend. Moreover, oil and gas are non-renewable and likely to run out in the near future. Current research on alternative energy to find the best alternative energy is ongoing.

Dimethyl ether (DME) is a substance that can be used as a liquefied petroleum gas (LPG) substitute because of their similar physical properties. DME is easier to liquefy than the LPG, giving advantages in terms of storage and transportation; moreover, it also has higher cetane value and smaller molecule which will be completely burnt benefitting the vehicle usage. It's also a nitrogen and sulphur lacked substrate; therefore, combustion of DME does not produce small particulates matters (PM), nitrogen oxides $\left(\mathrm{NO}_{\mathrm{x}}\right)$ and sulphur oxide $\left(\mathrm{SO}_{\mathrm{x}}\right)$. It can be said that DME is a clean alternative energy that is ideal for vehicle usage. The production of DME includes a wide variety of options ranging from simple reactordistillations, reactor-distillation-pervaporation, single reactive distillation, or multiple reactive distillations. Due to the complexity of the synthesis and design of the process, the optimum processing pathway is hardly accomplished.

The process synthesis and design through superstructure optimization could help identifying the most economical alternative via mathematical method. The conventional production pathways, as well as, newly generated alternatives are combined into the form of superstructure, the generic mathematical model is applied and solved using mixed-integer linear programming (MILP) embed in the GAMs software.

\section{Methodology}

The integrated business and engineering framework for synthesis and design of processing networks $[2,3]$ has been applied into this work. The potential alternatives for synthesizing and designing processes are presented as processes intervals; they are arranged in the form of superstructure as displayed in fig. 1. Raw materials are presented in the first column; while products are embodied in the last column. The processing steps sequentially proceed from the left- to the right-hand side of the superstructure, converting and/or separating the raw materials to the products.

Whereas, each process is presented through a generic process interval description displayed in fig. 2. Eqs. 1-7 are incorporated generic equations depicting the operation of a unit or a group of units.

\footnotetext{
${ }^{*}$ Corresponding author: amata.an@kmitl.ac.th
} 


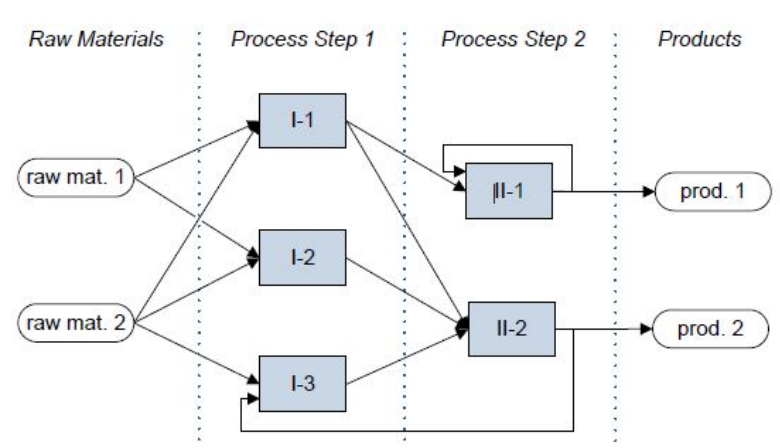

Fig. 1. Superstructure representation [3]

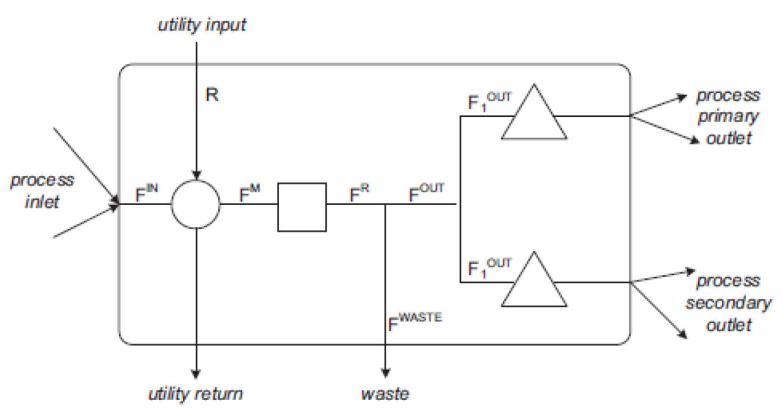

Fig. 2. Generic process interval [9]

$$
\begin{gathered}
F_{i, k k}^{M}=\sum_{k} F_{i, k, k k}+\alpha_{i, k k} \cdot R_{i, k k} \\
R_{i, k k}=\mu_{i, k k} \sum_{i, k} F_{i, k, k k} \\
F_{i, k k}^{R}=F_{i, k k}^{M}+\sum_{r r, r x}\left(\gamma_{i, k k, r r} \cdot \theta_{r x, k k, r r} \cdot F_{r x, k k}^{M}\right) \\
F_{i, k k}^{O}=F_{i, k k}^{R} \cdot\left(1-S W_{i, k k}\right) \\
F_{i, k k}^{W}=F_{i, k k}^{R}-F_{i, k k}^{O} \\
F_{i, k k}^{O M}=F_{i, k k}^{O} \cdot S F_{i, k k} \\
F_{i, k k}^{O S}=F_{i, k k}^{O}-F_{i, k k}^{O M}
\end{gathered}
$$

The mathematical model is formulated as mixedinteger linear programming problem with the objective function, the logical constraints, and the variable bounds defined as following by eqs. 8-12.

$$
\begin{array}{lc}
\max & f(x, y) \\
\text { s.t. } & g(x, y) \geq 0 \\
& h(x, y)=0 \\
& x^{L O} \leq x \leq x^{U P} \\
& y \in\{0 ; 1\}^{n}
\end{array}
$$

The objective function of this study is maximizing annual profit, in term of earnings before interest and taxes (EBITA), subject to logical decisions on choosing the unit operations and raw material flowrate.

\section{DME Production and alternatives}

\subsection{Conventional DME production}

The conventional production of DME by dehydration of methanol with the capacity 110 Mta has been reported by
Luyben [4]. The process consists of an adiabatic reactor, two distillation columns, and feed preheater as displayed in fig. 3. Feed, $153 \mathrm{Mta}$ of methanol, is preheated to 275 ${ }^{\circ} \mathrm{C}$ and then fed into the adiabatic reactor with solid catalyst. Methanol is undergoing the dehydration reaction; $82 \%$ of methanol is converted to DME with water as side product as displayed in eq. 13 .

$$
2 \mathrm{CH}_{3} \mathrm{OH} \leftrightarrow \mathrm{CH}_{3} \mathrm{OCH}_{3}+\mathrm{H}_{2} \mathrm{O}
$$

The reactor product is used for preheating the feed, then cooled down before sending to distillation column. The first column separates DME from methanol and water; DME, as top product, comes out at $99.999 \%$ purity. The methanol and water mixture at the bottom of the first column is then sent to second column. The unreacted methanol is separated in this column and recycled back to mix with the feed.

The capital cost of the conventional process is approximately 3.4 MM\$, with the net energy cost 2.6 $\mathrm{MM} \$ / \mathrm{y}$.

\subsection{Processing alternatives}

Pervaporation with alpha-alumina membrane has been reported employing for the separation between water and methanol by Chapman et al. [5]. Water-methanol are separated completely at $50{ }^{\circ} \mathrm{C}$ with $0.57 \mathrm{~kg} / \mathrm{m}^{2} \cdot \mathrm{h}$ flux. This unit can be used as a substitution for the second distillation column.

Reactive distillation (RD) has also been reported for the production of DME, both from pure methanol [6] and methanol in glycerol [7]. The RD can be applied as a combined reactor-separation to enhance the methanol conversion; as well as, employed as product enhancer after the conventional reactor; moreover, it can also be used to convert the recycled methanol to reduce the main reactor load [8]. Products of RD could be methanol, water, DME, or mixtures of different compositions of these compounds depending on the whereabout of the column. In this study, the RD is employed as the single unit process, and as enhanced-substitution of both distillation columns.

The important mixing, reacting, and separating parameters of the conventional and alternatives processes are reported in tables $1 \mathrm{a}-\mathrm{c}$, and the DME production superstructure is displayed in fig. 4.

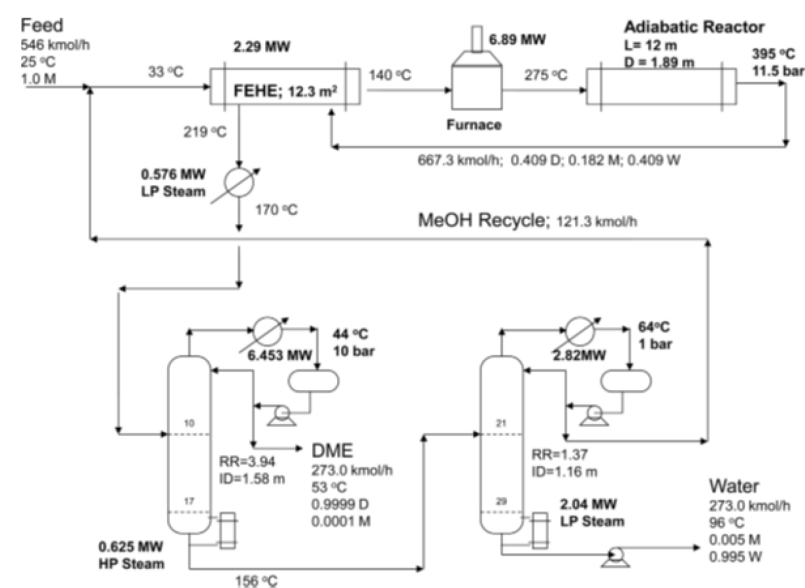

Fig. 3. Conventional DME production [4] 


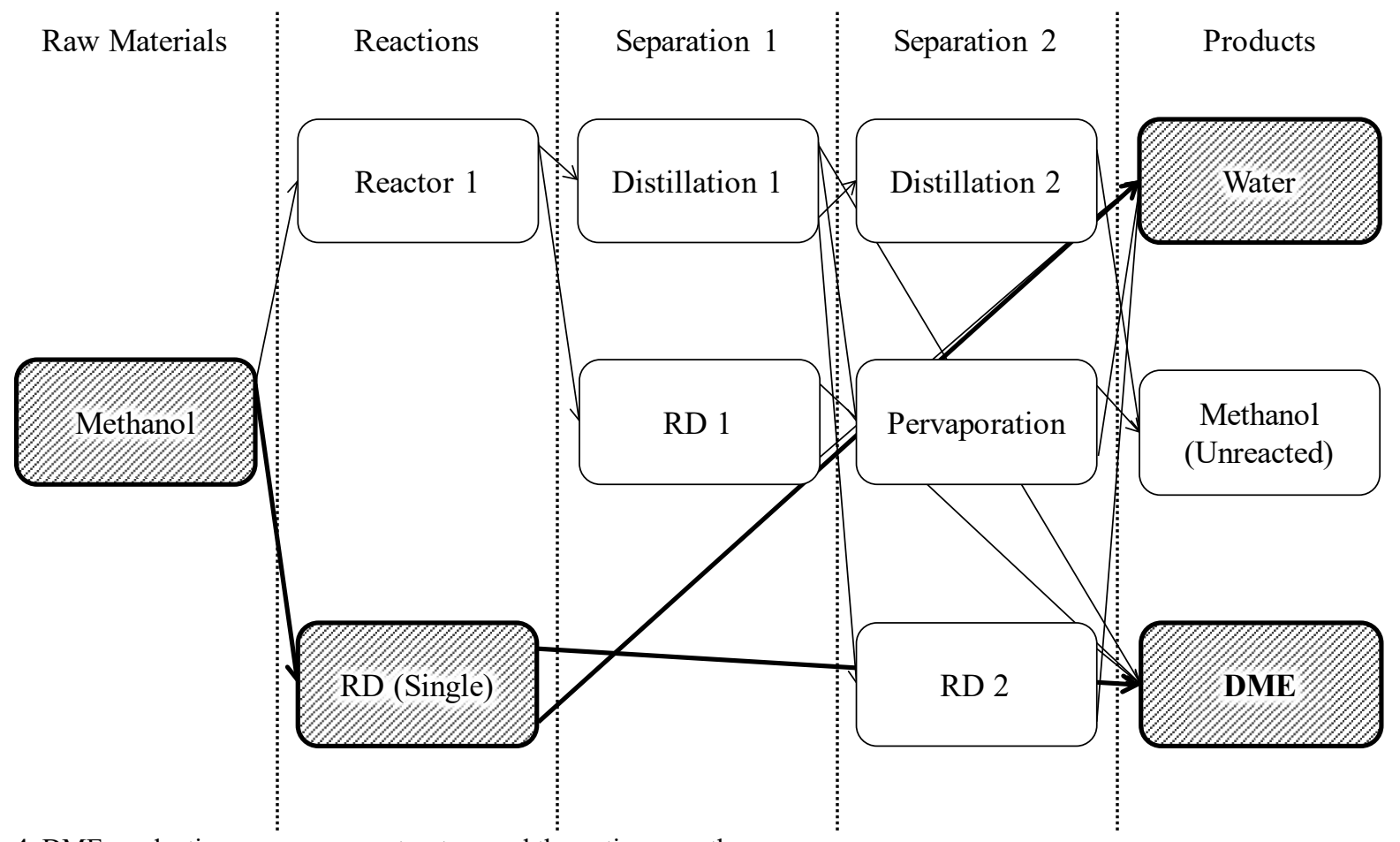

Fig. 4. DME production process superstructure and the optimum pathway

Table 1a. DME production processes reaction parameters

\begin{tabular}{lcccc} 
Intervals & $\theta_{M e O H}$ & $\gamma_{M e O H}$ & $\gamma_{D M E}$ & $\gamma_{W}$ \\
\hline Rx 1 & 0.409 & -2 & 1 & 1 \\
\hline RD (S.) & 0.5 & -2 & 1 & 1 \\
\hline RD 1 & 0.5 & -2 & 1 & 1 \\
\hline RD 2 & 0.5 & -2 & 1 & 1
\end{tabular}

Table 1b. DME production processes sepraration parameters

\begin{tabular}{lccc}
\hline Intervals & $S F_{M e O H}$ & $S F_{D M E}$ & $S F_{W}$ \\
\hline Dist. 1 & 1 & 0 & 1 \\
\hline Dist. 2 & 1 & 1 & 0 \\
\hline RD (S.) & 0 & 1 & 0 \\
\hline RD 1 & 0 & 1 & 0 \\
\hline RD 2 & 0 & 1 & 0 \\
\hline Perva. & 1 & 1 & 0
\end{tabular}

\section{Results}

Single reactive distillation operation has been chosen as the optimum production pathway for the dehydrogenation of DME, displayed as greyed box in fig. 4 .

Comparing to the conventional process, the optimum pathway requires only one preheater and one column; moreover, due to the parallel reacting-separating operation of the $\mathrm{RD}$, the reaction is shifted toward the product side, resulting in the increasing of the raw material conversion. An initial estimation is found that the capital investment of the optimum process is $2.3 \mathrm{MM} \$$, $32 \%$ lowering from the conventional process; additionally, the total operating cost (including net energy
Table 1c. DME production processes utilities parameters

\begin{tabular}{|c|c|c|c|c|}
\hline Intervals & $\mu_{\text {Pow }}$ & $\mu_{N G}$ & $\mu_{H P S}$ & $\mu_{C W}$ \\
\hline Rx 1 & 7.8 & 1.1 & & \\
\hline Dist. 1 & & & 61.2 & 52.0 \\
\hline Dist. 2 & & & 337.6 & 38.4 \\
\hline RD (S.) & 9.6 & & 1017.2 & 90.0 \\
\hline RD 1 & & & 641.0 & 63.8 \\
\hline RD 2 & & & 641.0 & 63.8 \\
\hline Perva. & 3.8 & & & 108.6 \\
\hline${ }^{*} \mu_{\text {Pow }}$ & \multicolumn{4}{|c|}{$\equiv \mathrm{kWh} /$ tonne } \\
\hline$\mu_{N G}$ & \multicolumn{4}{|c|}{$\equiv \mathrm{MMBTU} /$ tonne } \\
\hline$\mu_{H P S}$ & \multicolumn{4}{|c|}{$\equiv \mathrm{kg} /$ tonne } \\
\hline$\mu_{C W}$ & \multicolumn{4}{|c|}{$\equiv \mathrm{kg} /$ tonne } \\
\hline
\end{tabular}

cost) is approximately $2.2 \mathrm{MM} \$ / \mathrm{y}, 17 \%$ lower from the conventional operation.

The optimum process is then simulated in an open source process simulator DWSIM v.5.1. The result of the detailed simulation, as presented in fig. 5 , indicates that the 54 stages-RD column can produce up to $110 \mathrm{Mtonne} / \mathrm{y}$ of above $99.99 \%$ purity of DME with the column operating pressure 11 atm., column reflux ratio 6.2 and the column diameter $2.1 \mathrm{~m}$. Water, at above $99.99 \%$ purity, is also produced as a side product. The conversion of methanol reaches $100 \%$ with 34 reactive stages, and the methanol raw material is fed to the column at the $9^{\text {th }}$ stage.

The detailed simulated result confirms the feasibility of the superstructure optimization methodology. The obtained design reduces capital and operating costs; moreover, the amount of waste generated is also reduced due to the enhanced conversion. On the other hand, there 


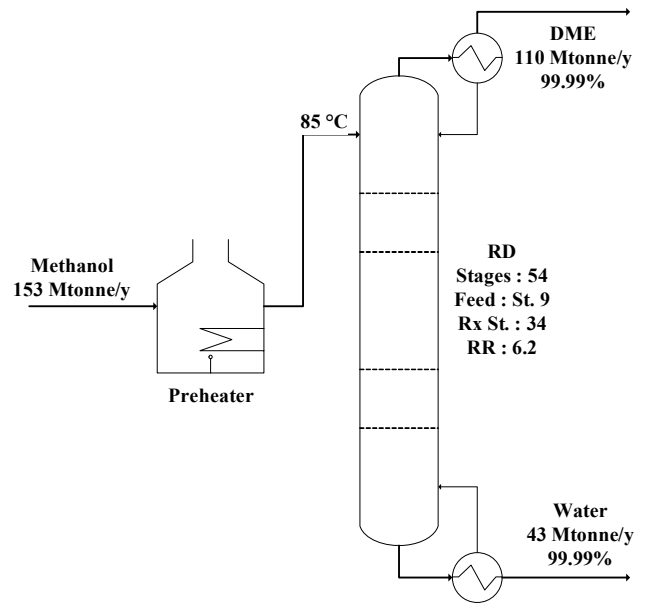

Fig. 5. Optimum DME production with single RD

is one particular disadvantage of the optimum design; since multiple units are integrated into one single unit, the degrees of freedom are reduced, and the controllability of the process is diminished.

Though, the result show promising design comparing to the conventional design, there are still room for the improvement regarding the energy integration such as the design displayed in fig. 6; more energy could be conserved by recycling the heat in the water from the column bottom

\section{Conclusion}

In this work, the integrated business and engineering framework for synthesis and design of processing networks has been adopted for the synthesis and design of the DME production.

The conventional DME production process, as well as, processing alternatives are collected and organized in form of the superstructure. The mathematical model has been formulated as the mixed-integer linear programming problem following the generic structure-interval model.

The MILP problem has been solved with the objective to maximize the annual profit (in term of EBITA). The obtained result selects single RD unit as the optimum design for the production of DME. The design has also been validated with the detailed simulation. The result

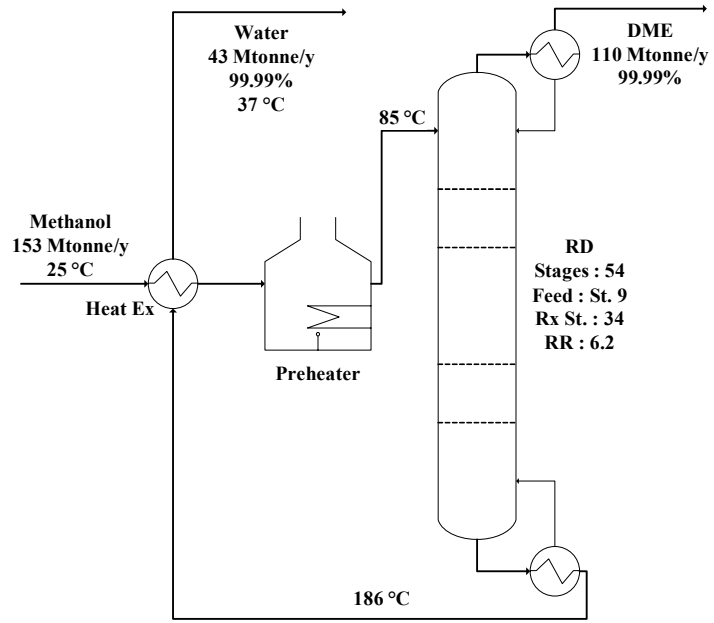

Fig. 6. Optimum DME production with single RD achieves $32 \%$ reduction of the capital investment and $17 \%$ reduction of the operating cost.

Despite achieving the optimum design with various improvements, the process can be further intensified for an even better result. The intensification step, specially, regarding energy intensification should also be included into the framework in the future.

\section{Nomenclature}

\begin{tabular}{|c|c|}
\hline \multicolumn{2}{|c|}{ Subscripts/ Superscripts } \\
\hline$i$ & Component \\
\hline$k, k k$ & Process Interval \\
\hline$r r$ & Reaction \\
\hline$r x$ & Key Reactant \\
\hline$M$ & After Mixing \\
\hline$O$ & After Waste Splitter \\
\hline$O M$ & Primary Outlet \\
\hline$O S$ & Secondary Outlet \\
\hline$R$ & After Reaction \\
\hline$W$ & Waste Stream \\
\hline \multicolumn{2}{|c|}{ Parameters/Variables } \\
\hline$F$ & Stream Flow \\
\hline$R$ & Utilities Flow \\
\hline$S W$ & Waste Split Fraction \\
\hline$S F$ & Stream Split Fraction \\
\hline$a$ & Utilities Mixed Fraction \\
\hline$\mu$ & Utilities/ Stream Ratio \\
\hline$\theta$ & Conversion \\
\hline Y & Stoichiometric Number \\
\hline \multicolumn{2}{|c|}{ Compounds/ Utilities } \\
\hline $\mathrm{MeOH}$ & Methanol \\
\hline$D M E$ & Dimethyl Ether \\
\hline$W$ & Water \\
\hline Pow & Power \\
\hline$N G$ & Natural Gas \\
\hline$H P S$ & High Pressure Steam \\
\hline$C W$ & Cooling Water \\
\hline
\end{tabular}

\section{References}

1. Enerdata, Global Energy Statistical Yearbook 2017 (2017).

2. A. Quaglia, B. Sarup, G. Sin, and R. Gani, Comput. Aided Chem. Eng. 30, 467 (2012).

3. A. Quaglia, B. Sarup, G. Sin, and R. Gani, Comput. Chem. Eng. 38, 213 (2012).

4. W. L. Luyben, Comput. Chem. Eng. 106, 17 (2017).

5. P. D. Chapman, T. Oliveira, A. G. Livingston, and K. Li, J. Memb. Sci. 318, 5 (2008).

6. A. Kiss and D. J.-P. C. Suszwalak, Procedia Eng. 42, 581 (2012).

7. P. Kaewwisetkul, L. Simasatitkul, and A. Arpornwichanop, Chem. Eng. Process. Process Intensif. 117, 80 (2017).

8. Z. Lei, Z. Zou, C. Dai, Q. Li, and B. Chen, Chem. Eng. Sci. 66, 3195 (2011).

9. A. Quaglia, B. Sarup, G. Sin, and R. Gani, Comput. Chem. Eng. 59, 47 (2013). 